\title{
Diamond-based electrodes for organic photovoltaic devices
}

\author{
Alexander Kovalenko ${ }^{1,2^{*}}$, Petr Ashcheulov ${ }^{3,4}$, Antonio Guerrero ${ }^{2}$, Patricie Heinrichová ${ }^{1}$, \\ Ladislav Fekete ${ }^{3}$, Martin Vala ${ }^{1}$, Martin Weiter $^{1}$, Irena Kratochvílová ${ }^{3}$, and Germà \\ Garcia-Belmonte ${ }^{2}$
}

1 Brno University of Technology, Faculty of Chemistry, Materials Research Centre, Purkyňova 118, 61200

Brno, Czech Republic

2 Photovoltaic and Optoelectronic Devices Group, Departament de Física, UniversitatJaume I, ES-12071

Castelló, Spain

3 Institute of Physics, Academy of Sciences Czech Republic v.v.i, Na Slovance 2, CZ-182 21, Prague 8, Czech

Republic

4 Faculty of Nuclear Physics and Physical Engineering, Czech Technical University in Prague, Zikova 1, 16000

Prague 6, Czech Republic

Email: kovalenko@fch.vutbr.cz,tel:00420775377415

\begin{abstract}
The present paper demonstrates the possibility of replacing indium tin oxide (ITO) with heavily boron-doped diamond (BDD). Plasma Enhanced Chemically Vapor Deposited BDDs of various thicknesses were prepared containing various boron concentrations in a gas phase. The dependence of the above-mentioned parameters on the optical and electrical properties of each BDD was studied in order to achieve optimal conditions for the effective application of diamond electrodes in organic electronics as a replacement for ITO. Bulk-heterojunction polymer-fullerene organic solar cells were fabricated to test the potency of BDD application in photovoltaic devices. The obtained results demonstrated the possibility of the aforementioned application. Even though the efficiency of BDDbased devices is lower compared to those using regular ITO-based architecture, the relevant issues were explained.
\end{abstract}

Published in Solar Energy Materials \& Solar Cells 2015, 134, 73-79 


\section{Introduction}

Today, the development potential of organic electronics can hardly be overestimated [1]. In an age of silicon devices, it is worth noting that, although silicon is inexhaustible, its purification, processing and utilization are not as ecologically friendly as could be desired. Organic electronic devices, meanwhile, are beginning to enter many fields of science and technology due to their many clear advantages. Owing to its low production temperatures, organic electronics does not require large energy consumption, which makes such electronics, along with the non-toxicity of its component materials, much more environmentally friendly in comparison with commonly used inorganic semiconductors. Similarly to silicon, organic materials are practically unlimited, but much easier to utilize. Specifically, due to their particular properties, they are flexible, adaptive to many types of surfaces, and virtually unbreakable.

In spite of the fact that organic electronics seems to be the technology of the future, some technological steps remain un- or underdeveloped, which significantly thwarts the infusion of this technology. Considering organic solar cells, which seem to have particular potential, one of the limiting factors is the development of transparent electrodes. At first glance, the widely-used compound indium tin oxide (ITO) seems to be the perfect candidate as a material for transparent electrode, as it exhibits superior transparency and a sheet resistance of below $100 \Omega / \square$. However, the declining availability of indium compels us to look for an alternative solution.

One possibility is to substitute ITO with carbon-based electrodes such as heavily boron-doped conductive diamond polycrystalline films [2]. Polycrystalline diamond films can be produced by a large variety of chemical deposition techniques, such as hot filament deposition [3], bias enhanced deposition [4], and Plasma-Enhanced Chemical Vapor Deposition (PECVD) with linear antenna delivery, where precursor gases are ionized to enhance their chemical reaction rates $[5,6]$. One of the advantages of the PECVD technique is the possibility to operate on a large variety of substrates at low deposition temperatures, which can be a crucial condition in the manufacture of semiconductors. With respect to photovoltaic devices, light-harvesting materials can be directly manufactured by the PECVD process $[7,8]$. Diamond is recognized to be a remarkable material due to its particularly attractive properties combining chemical resistance, optical transparency, thermal conductivity [9-13], and electrochemical properties [14-18]. Once successfully doped, diamond, which is generally recognized as an insulating material, becomes a wide-band gap semiconductor material with excellent potential due to the unique combination of its physical and electronic properties. The boron atom seems to be the only efficient dopant atom in diamond, which can be incorporated with high reproducibility and at a concentration high enough to be useful for electronic devices [15-19]. The physical properties of lightly-doped semiconductors are described in terms of band structures and impurity levels - the phenomenon of the formation of an impurity band was observed even at room temperature $[17,18]$. In the present paper, the possibility of replacing ITO with boron-doped diamond is described.

The addition of boron has a strong influence on the electrical conductivity of diamond layers [19-27]. For moderate boron concentrations - below $3 \times 10^{20} \mathrm{~cm}^{-3}$ - standard conductivity values for diamond layers were found $[19,28]$. Higher boron concentrations typically result in conductive systems with electrical properties comparable to metallic materials; also, superconductivity was reported by Ekimov et al [13] in heavily B-doped diamond. There are also other parameters which influence boron-doped diamond layer charge transport properties - namely, the electronic structures of boron defects, the morphology of the nanodiamond layer (the addition of boron has a strong influence on the morphology of the layers grown $[12-14,20])$, and the relative amount of $\mathrm{sp}^{2}$ and $\mathrm{sp}^{3}$ hybridized carbon in the nanodiamond layer [29-31]. The optimization of growth conditions at high boron/carbon ratios (up to $8000 \mathrm{ppm}$ in the gas phase during growth) can lead to low sheet resistance comparable to, or even lower than the best ITO samples. 


\section{Experimental}

\subsection{Diamond electrodes fabrication}

One of the main tasks was the proper patterning of the glass substrates for the subsequent measurements of the solar cells' power conversion efficiency (PCE). Prior to the growth of the diamond layer, glass substrates were screened with a pattern mask, which enabled the area on top of the substrates to be covered with electrode channels $8 \mathrm{~mm}$ in width. The substrates were then seeded with a nanodiamond particle solution which was sonicated before seeding in order to break up large clusters in dispersion. The mean size of the nanodiamond seeds in the solution was 5-10 nm as measured by dynamic light scattering (DLS) after sonication. Then, the glass substrates were cleaned in isopropyl alcohol (IPA) and subsequently dipped into the diamond dispersion. In order to produce a monolayer of nanodiamond seeds on the glass substrate surface, the seeding solution was deposited by spin coating for 30 seconds at $3000 \mathrm{rpm}$. This procedure resulted in homogenous coverage of the patterned substrates with a nucleation seed density of approximately $10^{10} \mathrm{~cm}^{-2}$ as measured by Atomic Force Microscopy (AFM).

After the patterned seeding on glass substrates was prepared, boron-doped diamond (BDD) nanocrystalline films were grown by a chemical vapor deposition technique. A SEKI ASTeX 5010 Microwave Plasma Enhanced CVD reactor was used to grow the BDD layers. Growth was performed in $\mathrm{CH}_{4} / \mathrm{H}_{2}$ plasma with a respective gas concentration ratio of $5 \% / 95 \%$. Boron doping was achieved by adding trimethylboron $(\mathrm{TMB})$ to the gas mixture. The substrate temperature $\left(700^{\circ} \mathrm{C}\right)$ during the BDD growth process was monitored by a Williamson Pro 92-38 dual-wavelength infrared pyrometer. By varying the $B / C$ concentrations (from 2000 to $8000 \mathrm{ppm}$ ) during the growth process, layers with different doping levels were obtained. In order to obtain optically transparent electrodes, BDD layers with various thicknesses were produced.

\subsection{Diamond film characterization techniques}

Several characterization techniques were applied to investigate the properties of the boron-doped diamond films. In order to reveal the $\mathrm{sp}^{3} / \mathrm{sp}^{2}$ ratio (the presence of amorphous and graphitic phases) throughout the layer, Raman spectroscopy measurements were carried out. Spectra were taken at room temperature using a Renishaw InVia Raman microscope under the following conditions: wavelength $-488 \mathrm{~nm}(25 \mathrm{~mW})$; objective $-\times 50$ Olympus; slit size $-65 \mu \mathrm{m}$; type of focus - spot focus; grating $-2400 \mathrm{l} / \mathrm{mm}$.

The conductivity and Hall constant were measured by the differential van der Pauw method using a Keithley 6221 current source and two electrometers, a Keithley 6514 with nano-voltmeter, and a Keithley 2182A, which recorded the voltage difference between the electrometers. A pulsed (quasiDC) measuring mode was used to compensate for parasitic thermoelectric signals. All electrical measurements were performed in the dark at room temperature $(296 \pm 1 \mathrm{~K})$. In all films investigated, the resistivity was measured with an error not exceeding 1-2\%, while the Hall constant and mobility were determined with an accuracy of about $5 \%$. For the electrical characterization of BDD films, titanium $(20 \mathrm{~nm}) /$ gold $(100 \mathrm{~nm})$ triangle contacts were evaporated.

Surface roughness, morphology, and film thickness were investigated by AFM using an NTEGRA Prima NT-MDT system under ambient conditions. Samples were scanned using an HA_NC Etalon tip in semi contact mode. A local contrast (LC) filter was applied to all images to better visualize each film's morphology.

The transmittance spectra of samples were characterized by a Varian Cary Probe 50 UV-VIS spectrometer (Agilent Technologies Inc., Santa Clara, CA, U.S.A.). The integral value of transmittance was determined by integrating spectral data in the range $300-850 \mathrm{~nm}$. Commercially available ITO/glass reference substrates were purchased from Sigma Aldrich. The thickness of the reference 
ITO samples was $60-100 \mathrm{~nm}$, with an electrical conductivity of $\sim 50 \Omega / \square$, as measured by the 4 probe method.

\subsection{Materials}

P3HT (Luminescence Technology Corp.), PC 60 BM (Solenne, 99 \%), o-dichlorobenzene (Aldrich, 99.9 $\%), \mathrm{ZnO}$ nanoparticles dispersed in IPA (Gene's Ink), $\mathrm{Ca}$ (Aldrich, $99.995 \%$ ), $\mathrm{MoO}_{3}$ (Aldrich, $99.98 \%$ ) and $\mathrm{Ag}$ (Aldrich, $99.99 \%$ ) were used as received without further purification. The active layer films were prepared from a $\mathrm{P} 3 \mathrm{HT}: \mathrm{PC}_{60} \mathrm{BM}$ solution (1:0.8 by weight) in o-dichlorobenzene and were stirred for 12 hours at $80^{\circ} \mathrm{C}$ until complete dissolution. The concentrations of the pure $\mathrm{P} 3 \mathrm{HT}$ and $\mathrm{PC}_{60} \mathrm{BM}$ solutions in o-dichlorobenzene solvent were $17 \mathrm{mg} \mathrm{mL}^{-1}$ and $13.6 \mathrm{mg} \mathrm{mL}^{-1}$, respectively. All manipulations were carried out in a glove box under a nitrogen atmosphere unless otherwise stated.

\subsection{Device fabrication}

Inverted architecture $\mathrm{P} 3 \mathrm{HT}: \mathrm{PC}_{60} \mathrm{BM}$ devices were fabricated using the regular procedure [32-34]. After boron-doped diamond electrodes were grown, substrates were cleaned ultrasonically in $10 \%$ $\mathrm{NaOH}$ solution for $5 \mathrm{~min}$, in deionized water for $15 \mathrm{~min}$, and finally in IPA for 10 min to remove residual impurities. The cleaned substrates were covered by a $\mathrm{ZnO}$ suspension by spin-coating at $2000 \mathrm{rpm}$ for $40 \mathrm{~s}$ at ambient atmosphere, and further annealed at $75^{\circ} \mathrm{C}$ for 45 seconds. Prior to deposition, the $\mathrm{ZnO}$ was filtered through a $0.45 \mathrm{~mm}$ nylon filter.

$100 \mathrm{~nm}$ polymer-fullerene heterojunction layers were prepared by spin coating $55 \mu \mathrm{l}$ of $\mathrm{P} 3 \mathrm{HT}: \mathrm{PC}_{60} \mathrm{BM}$ solution at $1200 \mathrm{rpm}$ for 15 seconds in a nitrogen atmosphere and then immediately placed into a closed petri dish for 60 minutes for solvent annealing. The devices were further thermally annealed at $130^{\circ} \mathrm{C}$ for 10 minutes. Top electrodes $\left(7 \mathrm{~nm}\right.$ of $\mathrm{MoO}_{3}$ and the subsequent evaporation of $100 \mathrm{~nm}$ of $\mathrm{Ag}$ ) were deposited by vacuum evaporation.

\subsection{Solar cell characterization techniques}

Current density-voltage measurements were carried out under illumination using an Abet Sun 2000 solar simulator with an air mass (AM) $1.5 \mathrm{G}$ filter. The simulated light intensity was adjusted to 1000 $\mathrm{Wm}^{-2}$ by using a NREL-calibrated Si solar cell.

Capacitance-voltage and impedance spectroscopy data were acquired using an Autolab PGSTAT-30 equipped with a frequency analyzer module. 


\section{Results and Discussion}

\subsection{Diamond layers characterization}

Table 1: Diamond layer growth parameters:

\begin{tabular}{|r|r|r|r|r|}
\hline $\begin{array}{l}\text { Sample } \\
\text { No }\end{array}$ & $\begin{array}{l}\text { B/C, } \\
\text { ppm }\end{array}$ & \multicolumn{1}{l|l}{$\begin{array}{l}\text { Time, } \\
\text { min }\end{array}$} & d[nm] & $\rho[\Omega / \square]$ \\
\hline 1 & 2000 & 30 & 71 & 50000 \\
\hline 2 & 2000 & 60 & 148 & 910 \\
\hline 3 & 2000 & 120 & 281 & 50 \\
\hline 4 & 2000 & 240 & 466 & 48 \\
\hline 5 & 4000 & 30 & 65 & 1100 \\
\hline 6 & 4000 & 60 & 167 & 140 \\
\hline 7 & 4000 & 120 & 300 & 39 \\
\hline 8 & 4000 & 240 & 416 & 26 \\
\hline 9 & 8000 & 30 & 90 & 185 \\
\hline 10 & 8000 & 60 & 114 & 240 \\
\hline 11 & 8000 & 120 & 219 & 80 \\
\hline 12 & 8000 & 240 & 481 & 21 \\
\hline
\end{tabular}

Electrical measurements revealed that the conductivity of the BDD layers is correlated to the size of the grains in the layer. Indeed, for the same B/C ratio, thicker layers are less resistive, as can be seen from Table 1 and S1. This effect is attributed to the size of the grains [30], as confirmed by AFM scans (Figure 1.). The magnitude of the sheet resistance, measured by the four point probe technique, was in the range from $21 \Omega / \square$ for the $481 \mathrm{~nm}$ thick sample prepared at an $8000 \mathrm{ppm} \mathrm{B/C}$ ratio to $5 \times 10^{5} \Omega / \square$ for the thin $70 \mathrm{~nm}$ diamond grown at the $2000 \mathrm{ppm} \mathrm{B/C} \mathrm{ratio} \mathrm{(Table} \mathrm{1).} \mathrm{Notably,} \mathrm{the} \mathrm{sheet}$ resistance of the reference ITO sample was $50 \Omega / \square$. Conductivity was found to be higher for thicker films with the same B content. One of the factors affecting conductivity is grain size. It has been reported [30] that films with a larger grain size possess higher conductivity due to the higher amount of boron atoms incorporated into the diamond lattice, while, in the case of smaller grain size films, a large amount of boron is located at the grain boundaries, which is consistent with previously reported theoretical predictions [35]. Although in the present case, metallic conductivity is highly desired; in the case of larger diamond grains a high degree of roughness can adversely affect the further processes of organic layer preparation.

Of all of the grown samples (table 1), sample № 3 (the $290 \mathrm{~nm}$ thick diamond) exhibited good conductivity with a sheet resistance of $50 \Omega / \square$ and a decent integral transparency value in the measured wavelength range of around $40 \%$, which is promising for ITO replacement applications. Thicker heavily boron-doped samples, i.e. those possessing better conductivity (a sheet resistance of up to $21 \Omega / \square$ for sample № 12), were much less transparent, and were not considered suitable for the desired application. Detailed data are shown in table S1.

All layers were investigated by AFM (see Figure 1.) and were found to be free of pinholes. The layers exhibited a distinct crystalline structure with grains showing a mixture of orientations. 

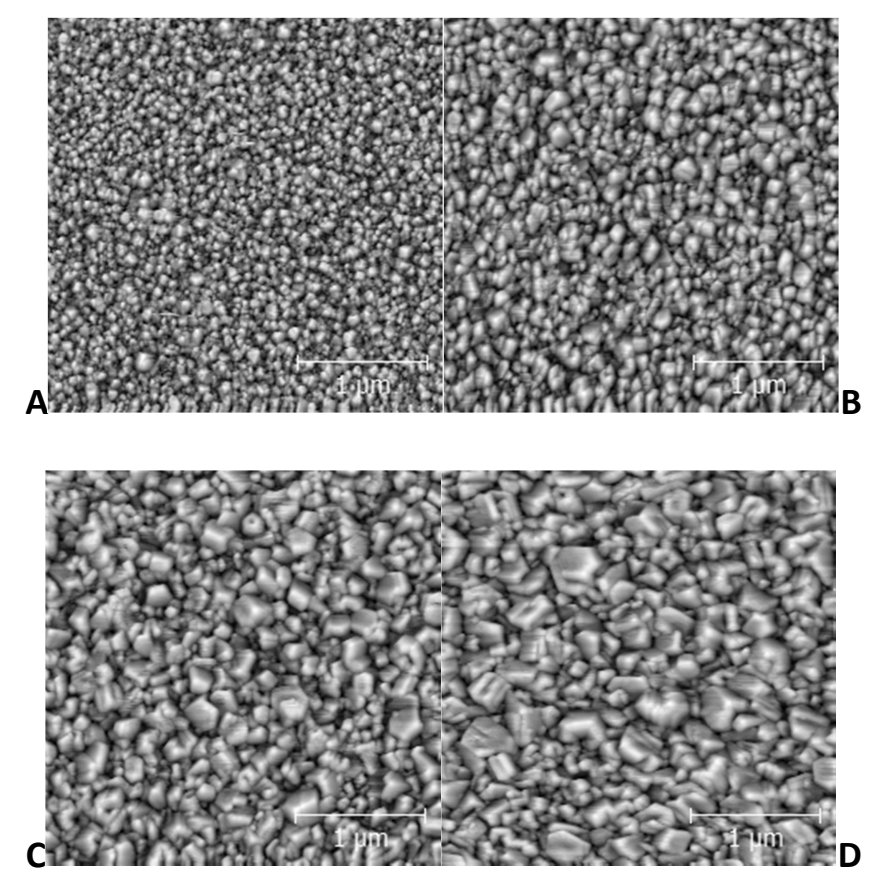

Figure 1: AFM images of BDD layers (grown at $4000 \mathrm{ppm}$ ) with Local Contrast filtering showing the change in morphology with increasing layer thickness. A) $65 \mathrm{~nm}$; B) $167 \mathrm{~nm}$; C) $300 \mathrm{~nm}$; D) $416 \mathrm{~nm}$.

Using Raman spectroscopy, peaks related to diamond $\left(\mathrm{sp}^{3}\right)$ and graphitic or amorphous carbon $\left(\mathrm{sp}^{2}\right)$ were detected for all layers investigated (Figure 2). A diamond peak was observed at $1322 \mathrm{~cm}^{-1}$ as well as broad features at $1150 \mathrm{~cm}^{-1}$ and $1490 \mathrm{~cm}^{-1}$, generally accepted as originating from transpolyacetylene at grain boundaries. Additional features were seen upon an increase in deposition time and TMB content, i.e. the appearance of broad peaks centered at 500 and $1225 \mathrm{~cm}^{-1}$, which were related to a locally distorted lattice structure induced by the addition of boron atoms. The crystalline diamond peak frequency exhibited a shift towards a lower wavenumber $\left(\sim 1295 \mathrm{~cm}^{-1}\right)$ upon increasing $B$ content. The shift in frequency towards lower wavenumbers was also seen for the broad $500 \mathrm{~cm}^{-1}$ band. Samples grown for longer deposition times exhibited an asymmetry $\left(1250-1328 \mathrm{~cm}^{-1}\right)$ in the spectra due to Fano-type interference between the discrete zone-center phonon and the continuum electronic states [36]. Notably, the Fano resonance just quenches the diamond line and does not mean a worsening of diamond quality.

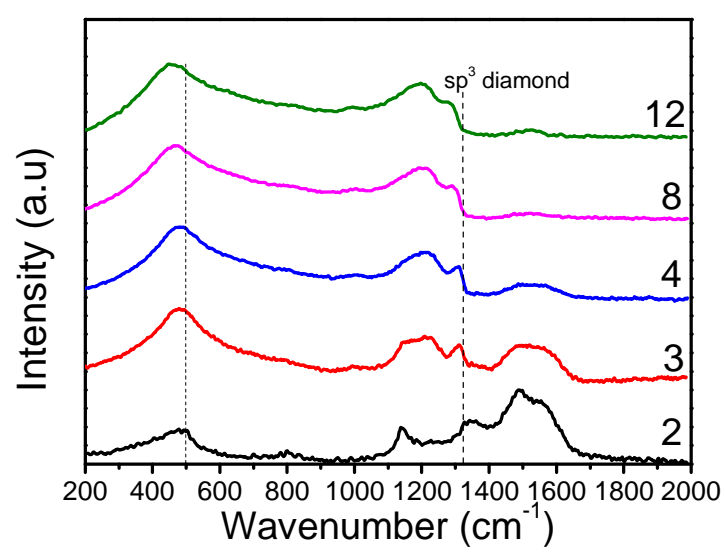

Figure 2: Raman spectra of boron-doped diamond layers grown with different amounts of TMB $(4,8,12)$ and for different deposition times $(2,3,4)$. The spectra were excited by $488 \mathrm{~nm}$ laser radiation and offset for clarity. 
Table 2 Electrical properties of the samples, measured at 300K.

\begin{tabular}{|l|l|l|l|l|l|}
\hline $\begin{array}{l}\text { Sample } \\
\text { No }\end{array}$ & $\begin{array}{l}\mathrm{B} / \mathrm{C} \\
\text { ratio } \\
(\mathbf{p p m})\end{array}$ & $\mathbf{d}(\mu \mathrm{m})$ & $\rho(\Omega \mathrm{cm})$ & $\begin{array}{l}\text { Carrier density } \\
\left(\mathbf{c m}^{-3}\right)\end{array}$ & $\begin{array}{l}\text { Carrier } \\
\text { mobility } \\
\left(\mathrm{cm}^{2} / \mathrm{Vs}\right)\end{array}$ \\
\hline 4 & 2000 & 0.466 & $9.07 \cdot 10^{-3}$ & $1.031 \cdot 10^{21}$ & 0.6674 \\
\hline 8 & 4000 & 0.416 & $4.35 \cdot 10^{-3}$ & $2.061 \cdot 10^{21}$ & 0.6959 \\
\hline 12 & 8000 & 0.481 & $5.98 \cdot 10^{-3}$ & $2.060 \cdot 10^{21}$ & 0.5064 \\
\hline
\end{tabular}

From table 2, which shows the electrical properties of the diamond samples grown at various $B / C$ concentrations, it can be seen that, at the $4000 \mathrm{ppm} \mathrm{B/C} \mathrm{ratio,} \mathrm{the} \mathrm{concentration} \mathrm{of} \mathrm{carriers} \mathrm{saturates}$ its maximum value, which can be explained by the dominant formation of boron-boron centers, as discussed in [37] as well as observed on the Raman spectra (figure 2) - the B-B peak increases both with $\mathrm{B} / \mathrm{C}$ concentration and layer thickness. The drop in carrier mobility for sample № 12 can be explained by the increasing concentration of scattering centers (defects) different from the regular $B$ acceptors. All the samples under study had a carrier density exceeding $10^{21} \mathrm{~cm}^{-3}$, which is characteristic of metallic conductivity. Compared to the carrier mobility of ITO $\left(10-50 \mathrm{~cm}^{2} / \mathrm{Vs}\right.$ $[38,39])$, that for diamond was determined to be two orders of magnitude lower.
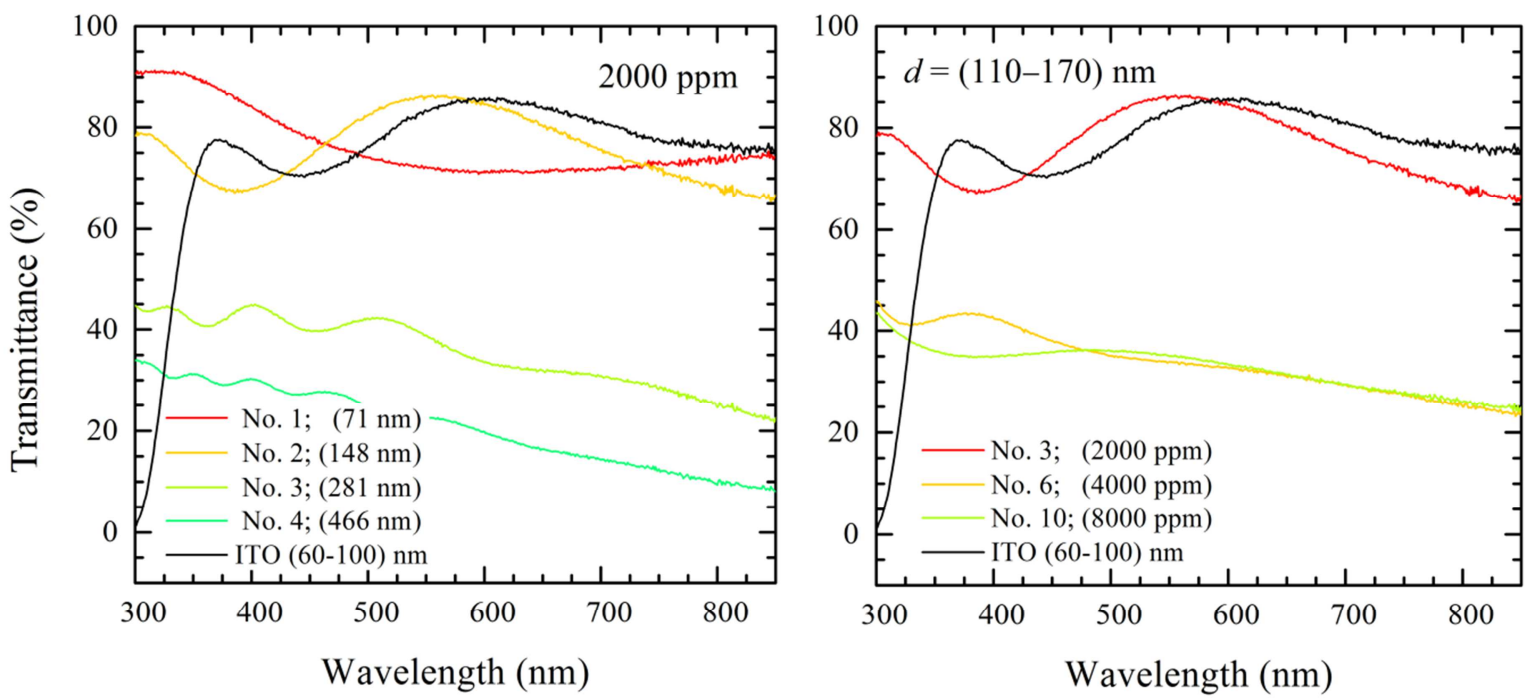

Figure 3: Transmittance spectra of diamond electrodes depending on thickness (left) and $B / C$ ratio (right).

Figure 3 depicts the dependences of diamond layer transmittance on layer thickness and B/C ratio. One can notice that the transmittance in the UV and visible spectra decreases with both the augmentation of boron during diamond growth and increasing layer thickness. The interpolated dependence of transmittance on conductivity is shown in figure 4. As can be observed, highly transparent diamond samples do not exhibit good conductivity; the most conductive sample with a transmittance of over $70 \%$ had a resistance $>10^{3} \Omega / \square$. For highly conductive BDD samples, the best transparency values achieved were about $40 \%$. 


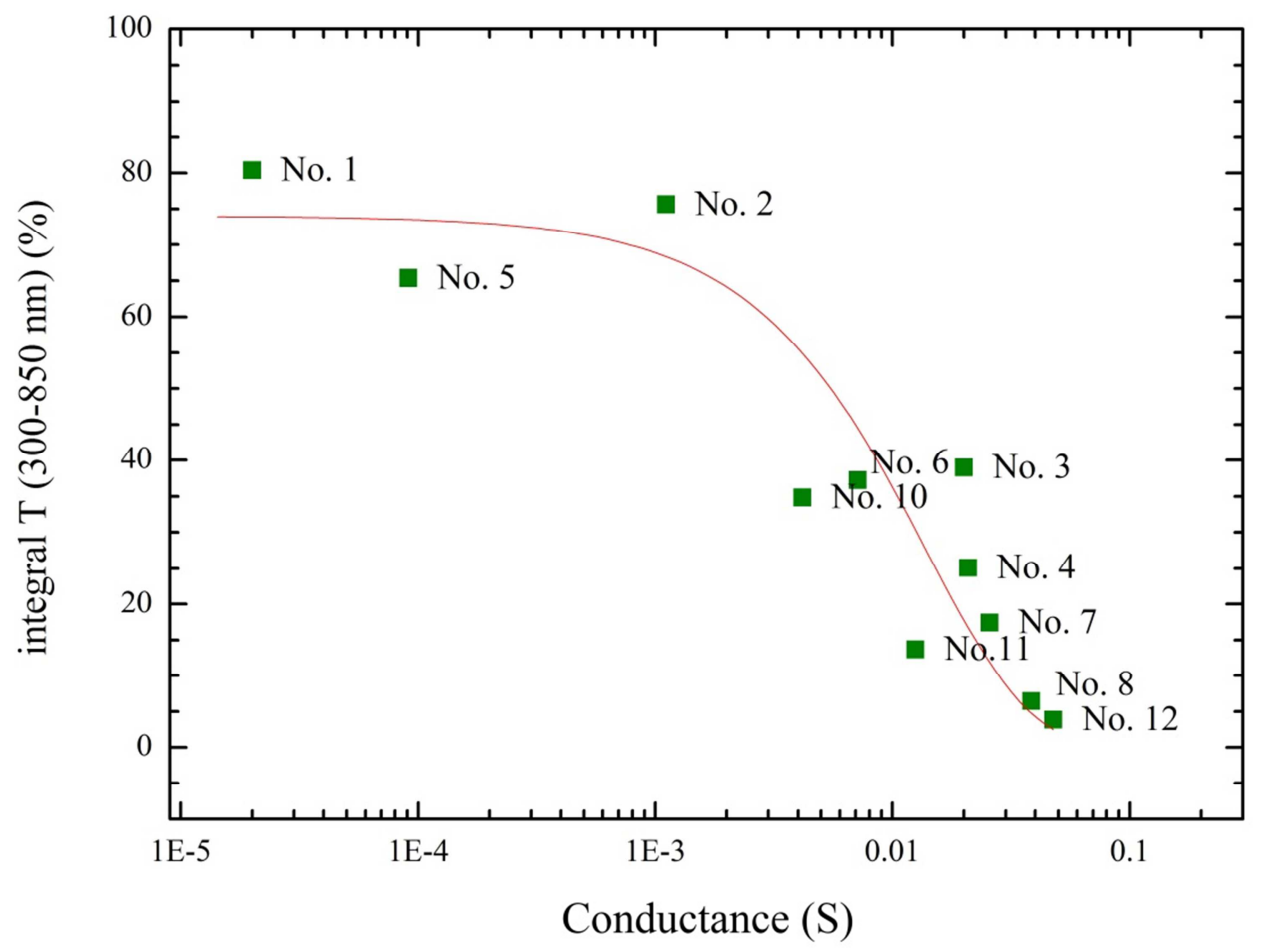

Figure 4: Dependence of transmittance on the conductivity of the considered diamond electrodes

Considering further aspects of the transparency vs. conductance issue, it can be noted that an increase in crystallite size, which can be controlled during the CVD process [40], will significantly decrease the proportion of grain boundaries in BDD films; thus, conductivity will significantly increase, although grain boundaries affect the transparency of the films due to the high $\mathrm{sp}^{2}$ ratio. In this case, the problem of greater diamond roughness caused by larger crystallite sizes can be solved by the previously reported process of plasma diamond polishing [41].

\subsection{Solar cells characterization}

A)

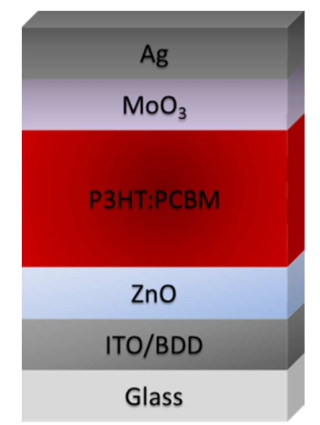

B)

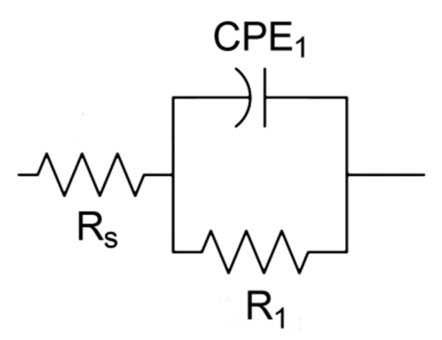

Figure 5: A) Scheme of the $\mathrm{P} 3 \mathrm{HT}: \mathrm{PC}_{60} \mathrm{BM}$ organic solar cell; B) equivalent circuit of the solar cell used in the impedance spectroscopy analysis, where $R_{s}$ - series resistance corresponding to the $\mathrm{BDD}(\mathrm{ITO}) / \mathrm{ZnO}$ interface; $\mathrm{R}_{1}$ - parallel (recombination) resistance; and $\mathrm{CPE}_{1}$ - constant phase element corresponding to the capacitance of the cell. 
Bulk-heterojunction solar cells were fabricated according to the aforesaid procedure with the inverted architecture (see Figure 5A). As is shown in table S1, out of all the prepared diamond samples the best efficiency was achieved by the solar cell based on sample № 3 possessing $0.91 \%$ of PCE, which was about $40 \%$ of that of the reference ITO-based BHJ solar cell. From table 3 and figure 4 , it can be seen that the main losses in efficiency were due to lower transparency resulting in lower current density in comparison with the reference cell; this also resulted in slightly lower $\mathrm{V}_{\mathrm{oc}}$.

Table 3: Main parameters of the reference ITO and Diamond-based BHJ solar cells:

\begin{tabular}{|l|r|l|l|l|l|}
\hline Device & \multicolumn{1}{l|}{$\mathbf{J}_{\text {sc }}$} & $\mathbf{V}_{\text {oc }}$ & \multicolumn{1}{l|}{$\mathbf{F F}$} & \multicolumn{1}{l|}{$\mathbf{E}_{\text {ta }}$} & \multicolumn{1}{l|}{$\boldsymbol{R}_{\text {shunt }}$} \\
\hline & {$\left[\mathrm{mA} / \mathrm{cm}^{2}\right]$} & {$[\mathrm{mV}]$} & \multicolumn{1}{l}{$[\%]$} & {$[\%]$} & {$\left[\mathrm{Ohm} \cdot \mathrm{cm}^{2}\right]$} \\
\hline Reference ITO & 7.32 & 565.62 & 56.74 & 2.35 & 9705 \\
\hline DiamondNo 3 & 3.34 & 533.82 & 50.68 & 0.90 & 1122 \\
\hline
\end{tabular}

One of probable reasons for the reduction in PCE could also be the roughness of the BDD electrodes, which was an order of magnitude higher than the roughness of commercially available ITO. As suggested by AFM measurements, this effect could have resulted in high-series resistance, even though the 4 point method revealed superior conductivity. Large surface roughness of the BDD substrate could have induced layer inhomogeneity [42] due to the fact that the measured surface roughness of the BDD samples was comparable with the thickness of the $\mathrm{P} 3 \mathrm{HT}: \mathrm{PC}_{60} \mathrm{BM}$ layer ( 100 $\mathrm{nm})$. In addition, and in general, the too close proximity of the diamond electrode to the Al layer can cause the appearance of conductive channels, which significantly reduces the fill factor of solar cells. Moreover, high roughness of the diamond electrodes hinders carrier transfer from the diamond cathode to $\mathrm{ZnO}$ nanoparticles.

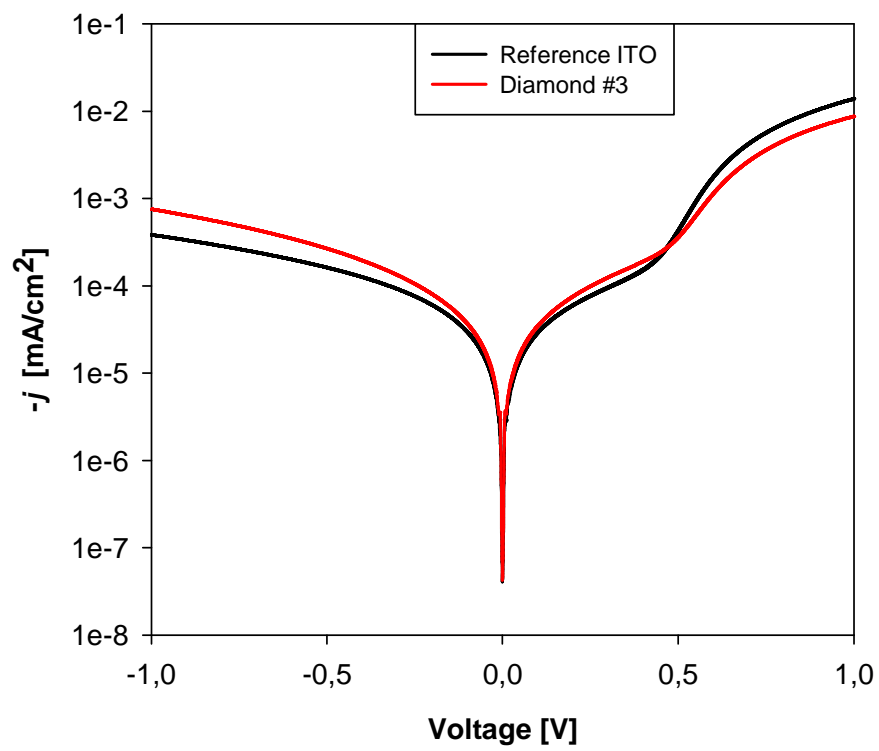

Figure 6: $\mathrm{JV}$ curve in the dark for $\mathrm{P} 3 \mathrm{HT}: \mathrm{PC}_{60} \mathrm{BM}$ solar cells based on diamond and reference ITO electrodes.

Figure 6 shows that a solar cell based on diamond electrodes possesses clear diode behavior. However, as already mentioned, due to higher diamond roughness and higher resistance, one can observe a slightly lower current density at forward diode characteristics as well as a higher leakage current at $-1.0 \mathrm{~V}$. From the J-V curve under 1 sun illumination (Figure 7.), it can be observed that the current density is much lower, which, as already mentioned, is because of the lower transparency of the BDD layers, and that the series resistance is notably higher, which results in a lower fill factor. 


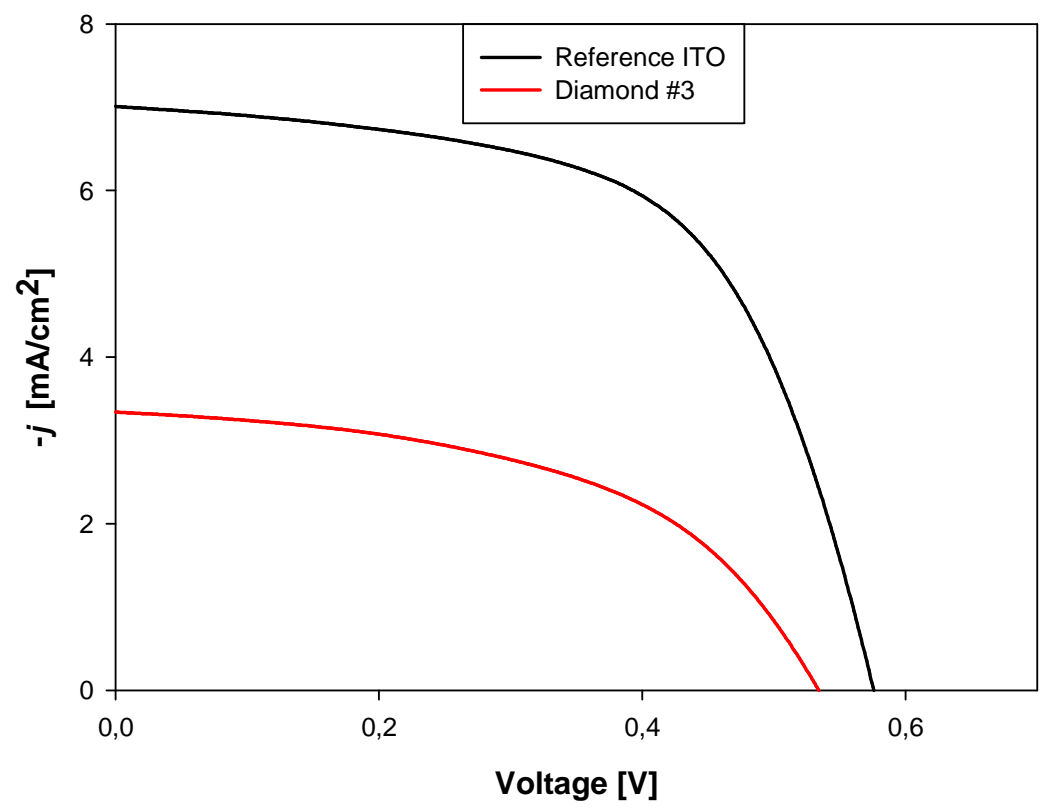

Figure 7: J-V curves of $\mathrm{P} 3 \mathrm{HT}: \mathrm{PC}_{60} \mathrm{BM}$ devices based on diamond and reference ITO electrodes.

The abovementioned devices were characterized by means of impedance spectroscopy in order to observe more closely the internal device structure and resistive contributions. As can be seen from table S1, the conductivity of sample № 3 was comparable with that of the reference ITO sample; however, the series resistance, measured by means of impedance spectroscopy $[43,44]$ using the equivalent circuit depicted in figure 5B, was approximately 3.3 times higher ( $264 \mathrm{Ohm}$ vs. $79 \mathrm{Ohm}$ ). In this case, the series resistance represents the $\mathrm{BDD}(\mathrm{ITO}) / \mathrm{ZnO}$ interface of the device, and, in the considered example, any significant increase in the resistance in comparison with direct measurements made by the 4 probe method determines the abovementioned resistive contributions at the interface. Even for samples whose conductivity exceeded that of ITO, the series resistance was higher. For example, the series resistance of the device based on sample № 8, which possessed a sheet resistance twice lower than the reference ITO, was found to be as high as $156 \mathrm{Ohm}$. This confirms the suggestion that significant roughness of the diamond layer plays a significant role in solar cell efficiency and can hinder electron transition at the diamond-ZnO interface. In light of this, a future step in this research area could be the use of electron/hole selective electrodes deposited on the diamond surface, which would not impede charge carrier transfer from the diamond to the selective contact. Several cross-linkable materials for hole-transport have been published, which could be useful in this respect [45, 46]; in-situ polymerized PEDOT:PSS [47] could be another option. However, in the present study, regular architecture devices with standard PEDOT:PSS as a hole selective layer did not present any advantages in PCE.Conclusion:

In this paper, the possibility of replacing ITO with boron-doped diamond was described. However, the obtained PCE values were much lower than the ones using ITO as a transparent electrode. Therefore, diamond could be considered to be a prospective material for electrodes as soon as the issue of transparency vs. conduction is resolved. The values of efficiency achieved can be compared with those obtained using graphene electrodes in organic BHJ solar cells [48]; however, the applied material is much cheaper and easier to produce. Nevertheless, "the golden mean" between such parameters as $B / C$ ratio and layer thickness still has to be found, as well as effective means of modifying such devices in order to increase PCE, e.g. by reducing diamond roughness and improving the purity of the diamond surface etc. In addition, the issues of low transparency and low carrier mobility still need to be resolved. Impedance spectroscopy, being a powerful tool for the 
characterization of solar cells, helped to reveal uncertainties in the device properties, which are caused mainly by the greater roughness of the diamond surface resulting in higher series resistance.

\section{Acknowledgement}

This work was supported by the Ministry of Education, Youth and Sport of the Czech Republic, project No. LO1211; by the Grant Agency of the Czech Republic, project No. 13-29358S; Technology Agency of the Czech Republic grant No. TA04020156, Generalitat Valenciana (project ISIC/2012/008 Institute of Nanotechnologies for Clean Energies) and European R\&D project FP7 ITN Grant No. PITNGA-2009-238201-MATCON. AK gratefully acknowledges financial support from Brno University of Technology via project CZ.1.07/2.3.00/30.0039. We are grateful to Pavel Hubik for assistance with Hall measurements.

\section{References:}

[1] H.Klauk, Organic Electronics: Materials, Manufacturing, and Applications, Wiley, 2006.

[2] Candy Haley Yi Xuan Lim, Yu Lin Zhong, StoffelJanssens, Milos Nesladek,and Kian Ping Loh, Oxygen-Terminated Nanocrystalline Diamond Film asan Efficient Anode in Photovoltaics, Adv. Funct. Mater. 20 (2010) 1313-1318.

[3] R Haubner, B Lux, Diamond growth by hot-filament chemical vapor deposition: state of the art, Diamond and Related Materials Volume 2, Issue 9, 1 July 1993, Pages 1277-1294

[4]Hiromasa Yagi, Kimihiko Hoshina, Akimitsu Hatta, Toshimichi Ito, Takatomo Sasaki and Akio Hiraki, Initial Stage of Bias-Enhanced Diamond Nucleation Induced by Microwave Plasma, 1997 Jpn. J. Appl. Phys. 36 L507

[5] Veprek, S., 1985. Plasma-Induced and Plasma-Assisted Chemical Vapor Deposition, Thin Solid Films 130, p.135.,

[6]Katsuyuki Okada, Plasma-enhanced chemical vapor deposition of nanocrystalline diamond, 2007 Sci. Technol. Adv. Mater. 8624

[7] Zhigang Zang, Atsushi Nakamura, and Jiro Temmyo, Single cuprous oxide films synthesized by radical oxidation at low temperature for PV application, Optics Express, Vol. 21, Issue 9, pp. 1144811456 (2013),

[8] Zhigang Zang, Atsushi Nakamura, Jiro Temmyo, Nitrogen doping in cuprous oxide films synthesized by radical oxidation at low temperature, Mater Lett 2013;92:188-191

[9] J.E. Field, The Properties of Diamond, Academic Press, New-York NY, 1979.

[10] K. Kobashi, Diamond Films, Elsevier, Oxford, UK, 2005.

[11] I. Kratochvílová, A. Kovalenko, F. Fendrych, V. Petráková, S. Záliš, M. Nesládek, Tuning of nanodiamond particles' optical properties by structural defects and surface modifications: DFT modeling, J. Mater. Chem. 21 (2011) 18248-18255.

[12] V. Petráková, A. J. Taylor, I. Kratochvílová, F. Fendrych, J. Vacík, J. Kučka, J. Štursa, P. Cígler, M. Ledvina, A. Fišerová, P. Kneppo, M. Nesládek, Luminescence of Nanodiamond Driven by Atomic Functionalization: Towards Novel Biomolecular Detection Principles, Adv. Funct. Mater.22 (2012) 812-819.

[13] I. Kratochvílová, A. Kovalenko, A. Taylor, F. Fendrych, V. Řezáčová, J. Vlček, S. Záliš, J. Šebera, P. Cígler, M. Ledvina, M. Nesládek, Fluorescence of Variously Terminated Nanodiamond Particles: Quantum Chemical Calculations, Phys. Status Solidi A, (2010) 1-4.

[14] S. Koizumi, C. Nebel, and M. Nesladek, Physics and Applications of CVD Diamond, Wiley-VCH Verlag GmbH \&Co.KGaA,Weinheim, Germany, 2008.

[15] E.A. Ekimov, V.A. Sidorov, E.D. Bauer, N.N. Melnik, N.J. Curro, J.D. Thompson, S.M. Stishov, Superconductivity in diamond, Nature 428 (2004) 542-525.

[16] J. Mort, D. Kuhman, M. Machonkin et al., Boron doping of diamond thin films, Applied Physics Letters, vol. 55, no. 11 (1989) 1121-1123. 
[17] J.C. Bourgoin, J. Krynicki, B. Blanchard, Boron concentration and impurity-to-band activation energy in diamond, Phys. Stat. Sol. (a) 52 (1979) 293.

[18] Rinat F. Mamin and Takashi Inushima, Conductivity in boron-doped diamond, Physical Review B, vol. 63, (2001) 033201.

[19] Y. Takano, et al., Superconductivity in polycrystalline diamond thin films, Diamond Relat. Mater.14, (2005) 1936.

[20] H. Okazaki, T.Arakane, K.Sugawara et al., Photoemission study of electronic structure evolution across the metalinsulator transition of heavily B-doped diamond, Journal of Physics and Chemistry of Solids 72 (2011) 582-584.

[21] Li Niu, Jia-Qi Zhu, Xiao Han et al., First principles study of structural, electronic and vibrational properties of heavily boron-doped diamond, Physics Letters A, 373 (2009) 2494-2500.

[22] I.I. Vlasov, E.A. Ekimov, A.A. Basov, E. Goovaerts, A.V. Zoteev, On the origin of the Raman scattering in heavily boron-doped diamond, arXiv:0801.1611 [cond-mat.mtrl-sci].

[23] Downs, R.T. and Hall-Wallace, M. The American Mineralogist Crystal Structure Database.American Mineralogist 88 (2003) 247-250.

[24] T. Hom, W. Kiszenick, Accurate lattice constants from multiple reflection mesurementsll.lattice constants of germanium, silicon and diamond, Post B Journal of Applied Crystallography 8 (1975) 457-458.

[25] J. P. Perdew, K. Burke, and M. Ernzerhof, Generalized Gradient Approximation Made Simple, Phys. Rev. Lett. 77 (1996) 3865.

[26] H. J. Monkhorst and J. D. Pack, On Special Points for Brillouin Zone Integrations, Phys. Rev. B 13, (1976) 5188.

[27] S. J. Clark, M. D. Segall, C. J. Pickard, P. J. Hasnip, M. J. Probert, K. Refson, M. C. Payne; First principles methods using CASTEP, ZeitschriftfuerKristallographie 220 (2005) 567-570.

[28] M. Dračínský, L. Benda, P. Bouř, Ab-initio modeling of fused silica, crystal quartz, and water Raman spectra, Chemical Physics Letters 512 (2010) 54-59.

[29] Z. Vlčková-Živcová, O. Frank, V. Petrák, H. Tarábková, J. Vacík, M.Nesládek, L. Kavan, Electrochemistry and in-situ Raman spectroelectrochemistry of low and high quality boron doped diamond layers in aqueous electrolyte solution, ElectrochimicaActa V. 87 (2013) 518-525.

[30] P.W. May, W.J. Ludlow, M. Hannaway et al., Raman and conductivity studies of boron-doped microcrystalline diamond, facetted nanocrystalline diamond and cauliflower diamond films Diamond \& Related Materials 17 (2008) 105-117.

[31] W. Kaiser, W.L. Bond, Phys. Rev. 115 (1959) 857.

[32] Ng, A., et al., Annealing of P3HT:PCBM Blend Film-The Effect on Its Optical Properties. ACS Applied Materials \& Interfaces, 5(10) (2013) 4247-4259.

[33] Yang, X. and A. Uddin, Effect of thermal annealing on P3HT:PCBM bulk-heterojunction organic solar cells: A critical review. Renewable and Sustainable Energy Reviews, 30 (2014) 324-336.

[34] Guerrero, A., et al., Charge carrier transport and contact selectivity limit the operation of PTB7based organic solar cells of varying active layer thickness. Journal of Materials Chemistry A, 1(39) (2013) 12345-12354.

[35] A.S. Barnard, M. Strernberg, Substitutional Boron in Nanodiamond, Bucky-Diamond, and Nanocrystalline Diamond Grain Boundaries, J. Phys. Chem. B 110 (2006) 19307.

[36] U. Fano, Effects of Configuration Interaction on Intensities and Phase Shifts Phys. Rev. 124 (1961) 1866

[37] P. Ashcheulov, J. Šebera, A. Kovalenko, V. Petrák, F. Fendrych,M. Nesládek, A. Taylor, Z. VlckováŽivcová, O. Frank,L. Kavan, M. Dracínský, P. Hubík, J. Vacík, I. Kraus, andl. Kratochvílová, Eur. Phys. J. B 86 (2013) 443.

[38] E. Terzini, P. Thilakan, C. Minarini, Mater. Sci. Eng., B77 (2000) 110.

[39] C. Liu, T. Matsutani, T. Asanuma, M. Kiuchi, Nucl. Instrum.Methods Phys.Res, Sect. B, 18 (2003) 253.

[40] Moran, Mark B.; Johnson, Linda F.; Klemm, Karl A., Control of crystallite size in diamond film chemical vapor deposition, Patent Department of the Navy, Washington, DC., 1992navy.reptR....M 
[41] H. Buchkremer-Hermanns, C. Long, H. Weiss, ECR plasma polishing of CVD diamond films, Diamond and Related Materials Volume 5, Issues 6-8, May 1996, Pages 845-849

[42] Ch. Jonda, A. B. R. Mayer, U. Stolz, Surface roughness effects and their influence on the degradation of organic light emitting devices, Journal of Materials Science 35 (2000) 5645 - 5651

[43] Martin Knipper, Jurgen Parisi, Kevin Coakley, Christoph Waldauf, Christoph J. Brabec, and Vladimir Dyakonov, Impedance Spectroscopy on Polymer-Fullerene Solar Cells, Z. Naturforsch. 62a, 490 - 494 (2007),

[44] Germà Garcia-Belmonte, Antonio Guerrero, and Juan Bisquert, Elucidating Operating Modes of Bulk-Heterojunction Solar Cells from Impedance Spectroscopy Analysis, J. Phys. Chem. Lett., 2013, 4 (6), pp 877-886

[45] Michelle S. Liu, Yu-Hua Niu, Jae-Won Ka, Hin-Lap Yip, Fei Huang, Jingdong Luo, Tae-Dong Kim and Alex K.-Y. Jen, Thermally Cross-Linkable Hole-Transporting Materials for Improving Hole Injection in Multilayer Blue-Emitting Phosphorescent Polymer Light-Emitting Diodes, Macromolecules, 2008, 41 (24), pp 9570-9580,

[46] Mi Seon Junga, Woong Shina, Sang Jun Parka, Hyeri Youa, Jung Bae Parka, Hongsuk Suhb, Younhee Limc, Do Yeung Yoonc, Joo Hyun Kim, Synthesis and characterization of thermally crosslinkable hole injection polymer based on poly(10-alkylphenothiazine) for polymer light-emitting diode, Synthetic Metals Volume 159, Issues 19-20, October 2009, Pages 1928-1933

[47] Chiara Musumeci, James A. Hutchison and Paolo Samorì, Controlling the morphology of conductive PEDOT by in situ electropolymerization: from thin films to nanowires with variable electrical properties, Nanoscale, 2013,5, 7756-7761

[48] Y. Wang et al. Large area, continuous, few-layered graphene as anodes in organic photovoltaic devices. Applied Physics Letters, 95 (6) (2009) 063302.

\section{Supplementary materials}

Table S1. Summary of obtained sample parameters

\begin{tabular}{|c|c|c|c|c|c|}
\hline $\begin{array}{l}\text { Sample / } \\
\text { B/C ratio }\end{array}$ & RMS [nm] & $\begin{array}{l}\text { thickness[n } \\
\mathrm{m}]\end{array}$ & $\mathrm{R}$ [Ohm/sq] & $\mathrm{T}[\%]$ & $\eta[\%]$ \\
\hline Reference ITO & $1-2$ & $60-100$ & 50 & $>75$ & 2.35 \\
\hline 1. / $2000 \mathrm{ppm}$ & 8,8 & 71 & 50000 & 80,4 & -- \\
\hline 2. / $2000 \mathrm{ppm}$ & 9,2 & 148 & 910 & 75,6 & -- \\
\hline 3. / $2000 \mathrm{ppm}$ & 13,3 & 281 & 50 & 39,0 & 0.91 \\
\hline 4. / $2000 \mathrm{ppm}$ & 15,3 & 466 & 48 & 25,1 & 0.68 \\
\hline 5. / $4000 \mathrm{ppm}$ & 7,6 & 65 & 1100 & 65,4 & 0.52 \\
\hline 6. / $4000 \mathrm{ppm}$ & 8,9 & 167 & 140 & 37,2 & 0.67 \\
\hline 7. / $4000 \mathrm{ppm}$ & 14,4 & 300 & 39 & 17,4 & -- \\
\hline 8. / $4000 \mathrm{ppm}$ & 18 & 416 & 26 & 6,4 & 0.52 \\
\hline 9. / $8000 \mathrm{ppm}$ & 7,7 & 90 & 185 & 62,2 & 0.55 \\
\hline 10. / 8000 ppm & 8,8 & 114 & 240 & 34,8 & 0.61 \\
\hline 11. / $8000 \mathrm{ppm}$ & 12,9 & 219 & 80 & 13,7 & -- \\
\hline
\end{tabular}




\begin{tabular}{|l|r|r|r|r|r|}
\hline $12 . / 8000 \mathrm{ppm}$ & 23,3 & 481 & 21 & 3,9 & -- \\
\hline
\end{tabular}

